\title{
Corrigendum: Yield at Thermal Engines Internal Combustion
}

\author{
${ }^{1}$ Relly Victoria V. Petrescu, ${ }^{2}$ Raffaella Aversa, ${ }^{3}$ Bilal Akash, ${ }^{4}$ Ronald B. Bucinell, ${ }^{5}$ Juan M. Corchado, ${ }^{6}$ John \\ Kaiser Calautit, ${ }^{2}$ Antonio Apicella and ${ }^{1}$ Florian Ion T. Petrescu
}

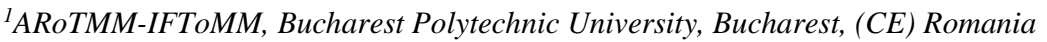 \\ ${ }^{2}$ Advanced Material Lab, Department of Architecture and Industrial Design, \\ Second University of Naples, 81031 Aversa (CE) Italy \\ ${ }^{3}$ Dean of School of Graduate Studies and Research, American University of Ras Al Khaimah, UAE \\ ${ }^{4}$ Union College, USA \\ ${ }^{5}$ University of Salamanca, Spain \\ ${ }^{6}$ Department of Mechanical Engineering, University of Sheffield, Sheffield, UK
}

Correction to: American Journal of Engineering and Applied Sciences http://doi.org/10.3844/ajeassp.2017.243.251, published online 18 March 2017; updated 29 August 2019

The original version of this Article contained Mr. MirMilad Mirsayar as a CoAuthor. Mr. Mirsayar has not contributed to the preparation and publication of this manuscript.

These errors have now been corrected in the HTML and PDF versions of the Article. http://doi.org/10.3844/ajeassp.2017.243.251. 